\title{
Ecological communications of modern students (experience of the Moscow automotive-road state technical university)
}

\author{
I. S. Voznesensky*, T. A. Mironova, and L. O. Ternovaya \\ Moscow Automobile and Highway State Technical University (MADI), Moscow, Russia
}

\begin{abstract}
The article presents the results of the analysis of the process of expansion and diversity of communication channels in the university environment, which is relevant from the standpoint of achieving the goals of sustainable development in the field of education. It is shown that one of the most accessible and open communication channels, in which modern students are actively involved, is the channel of environmental communications. They have many manifestations, which corresponds to the most exceptionally wide ecological space, reflecting both individual and collective interests, features of a narrow professional attitude to nature and its civilizational understanding. A significant part of the disciplines studied in higher education contributes to the formation of students' environmental competencies. The specificity of the ecological approach to education and upbringing contributes to involvement of students in activities for the nature protection. The regularities of environmental communications functioning can be traced on the example of environmental education carried out at the Moscow Automobile Road State Technical University (MADI).
\end{abstract}

\section{Introduction}

Scientists' attention to environmental problems became clearly visible when this environment began to show its unfriendly attitude towards humans. This process was triggered by accelerated industrialization. It began in the second half of the 19th century, when people from the countryside moved en masse to the sprawling cities. They got a job working for industrial enterprises, increasing the pressure on nature in the megalopolises formed at that time. Just then researchers began to show an increased interest in the issues of the relationship between man and nature. First of all, these were natural scientists, who felt and understood the fragility of the environment more subtly and better than others. The very concept of "ecology" arose, based on ancient Greek terms: oĩ place and $\lambda$ ó $\gamma \circ \varsigma$ - learning. The space was designated not only for scientific discourse, but also for social activity aimed at preserving nature. This required both development of the newest science - ecology, and allocation of environmental communication channels that could be filled with nature-saving meanings that attract caring people.

\footnotetext{
* Corresponding author: iv@sociomadi.ru
} 
Since any environmental issue is characterized by two parameters, the first of which is its transboundary nature, all-embracing, commonality for the entire planet, even despite the locality of any action, and the second is the impact not only on living people, but also on future generations, to involve young people in solving problems of nature protection is of special significance. This directs them towards a more conscious movement towards their own future and taking responsibility for it already in the present. For the full participation of young people in environmental initiatives, they must have the necessary competencies and be ready for the difficulties that arise in the process of environmental communications. Students receive the fundamentals of environmental knowledge from disciplines that are directly related to conservation issues. However, it is important that such information be supplemented with the skills to formulate an environmental problem, propose ways to solve it, as well as develop environmental communication skills even during the period of university studies, in order to demonstrate this knowledge, skills and abilities in subsequent work. The article presents some developments in this direction, accumulated by teachers of the Moscow Automobile and Road Construction State Technical University (MADI).

\section{Materials and methods}

The main source of the research presented in this article was the pedagogical practice at MADI, where environmental issues are widely introduced into the content of various training courses based on use of an integrative approach and use of transdisciplinary methods. To comprehend the experience gained while reading various academic disciplines, a systematic and comparative analysis of the results of students' mastering of environmental topics was used. Namely, a comparison of the methods and means of forming the environmental competence of students studying at universities in different countries was made, which showed that, despite the difference in training programs and the specifics of the educational and general socio-cultural environment, there are more common characteristics in the approaches to developing the foundations of environmental competence among students than differences. This allows a wider use of foreign experience in attracting students to environmental projects in the academic programs of Russian higher educational institutions. [12]

It also summarized the mutual influence of theory and practice in implementation of international strategies for the environmental education development, as part of the UNESCO strategy in the field of education for sustainable development (ESD). To identify the effectiveness of pedagogical technologies used to expand the ecological communications of students, the process of forming their ecological culture was modeled. Also, the diagnostics of the components of environmental communications was carried out, during which the methods of observation, questioning and graphical presentation of the students' environmental projects were used.

As a study innovation, the toolkit of the spiral dynamics concept was tested, which helps to analyze the human value world, organically inscribing environmental values into it, as well as to build the logic of the development of a value system in which environmental values are promoted to priority positions. [3, 4]

\section{Results and discussion}

To involve modern student youth in environmental communications, first of all, it is necessary to understand the nature of these actions, which over a relatively short period, covering a little more than a hundred years, from a narrow understanding of the dissemination of knowledge about the relationship between man and nature, have turned 
into an exceptionally wide field of interactions between individuals, groups, organizations, social movements on various aspects of environmental issues, and even opened up the possibility of connecting virtual participants to these activities.

The starting point for formation of ideas about environmental communications can be considered the decisions of the third International Botanical Congress (eng. International Botanical Congress), which was held in Brussels in 1910. Its participants identified three subsections of ecology: autoecology (ancient Greek av̉ ó $\varsigma$ - itself), synecology (from Greek $\sigma v v$ - together) and demecology (from ancient Greek $\delta \tilde{\eta} \mu \circ \varsigma$ - people). The first direction studies the interaction of an individual organism or species with the environment, in particular, it studies life cycles and behavior as a way of adapting to the environment. The second is interaction of populations of individuals of the same species within a given population and with its environment. The third direction studies the features of the functioning of communities and their interaction with biotic and abiotic factors. In fact, these branches of ecology shall be considered as the first channels of environmental communication identified by specialists.

Obviously, allocation of these subsections of ecology reflected not only the picture of biological science at the beginning of the 20th century, but also the fairly stable ideas that had developed by that time about the need to develop this area within oneself, to understand its specifics and highlight the basic positions. Under the influence of the changes associated with the scientific and technological revolution, the need to expand such channels and connect the subject area of ecology with other sciences and, in general, with the changing world outlook of a person was revealed. As a result, ecology has turned not into a narrow section of biology, but, on the contrary, a complex of sciences that study the functional relationships between organisms, which include humans and human society as a whole, and their environment, including the circulation of substances and energy flows that make life itself possible.

In this complex of sciences we see: bioecology, geoecology, geoethics, hydroecology, technoecology, landscape ecology, ethnoecology, medical ecology, social ecology, ecolinguistics, chemical ecology, radioecology, human ecology, antecology (ecology of flowering and pollination), information ecology and others branches of ecological knowledge. They also turn out to be communication channels both for communication within the actual ecological scientific space, and with adjacent areas, which are becoming more and more.

Insofar as the liberal model of management has become dominant in the promotion of global flows, the meanings of this management have penetrated into the understanding of the conditions for the emergence and definition of the framework of environmental communications. We see a clearer formulation of this framework already in the $21 \mathrm{st}$ century. This is undoubtedly due to the fact that environmental risks and challenges have jeopardized the continued existence of mankind. Environmental communications began to be identified as a separate scientific and at the same time practical problem when research on environmental ethics and ecolinguistics appeared. In the same period, experts noted the start of what was called "globalization", which allows us to say that environmental communications, on the one hand, opened with the beginning of globalization and, on the other hand, gave it a new impetus. [5, 6, 7]

According to R.J. Cox, former president of the Sierra Club that teaches rhetoric and communication courses at the University of North Carolina, the concept of environmental communication is based on three basic principles:

1. human communication is a form of a symbolic act;

2. beliefs, attitudes, behavior of people regarding nature and environmental problems are established by communication; 
3. the public sphere is a field for functioning and development of eco-communicative discourse. [8]

Cox identifies the following seven main areas of study and practice of environmental communication: environmental rhetoric and discourse; media and environmental journalism; public participation in environmental decision-making; social marketing and outreach campaigns; environmental cooperation and conflict resolution; risk communication; representations of nature in popular culture and green marketing. [8, p. 18]

Despite the fact that among the noted areas we do not find the field of education, it is present in environmental communications not only as an initial platform for development of environmental knowledge and the foundations of environmental behavior of students, but also as a space in which environmental rhetoric unfolds for a young person. In this regard, we can mention: Felix Finkbeiner, a German schoolchild from Bavaria, who initiated the planting of a million trees, for which he was awarded the Sea of Excellence-Avard prize for the best projects and ideas "with a view to the future"; Swedish schoolgirl, eco-activist Greta Thunberg, who promotes the version of the inevitable existential crisis of mankind due to the effects of climate change, which in 2019 was included in the list of the 100 most influential people in the world according to Time magazine and recognized by the same publication as "person of the year"; her young opponent from Germany, Naomi Seibt, who opposes environmental alarms.

More and more opportunities are opening up for young people to participate in environmental decision-making, namely, through participation in the eco-volunteer movement. In Moscow, young eco-volunteers in 2020 took part in the Clean Park action, the Zero Waste festival, a volunteer night at the Sborka eco-center, and also joined the celebration of the World Day of Cleanliness on September 18 and other events. Students within the framework of "Moscow cedar trees" project help workers of Moscow cedar mini-nurseries, and then plant small cedar trees in the territory of educational institutions of the Russian capital.

The fact that environmental communications actually permeate the educational process at all levels of education is drawn attention in UNESCO documents. Namely, the UNESCO Strategy "Education for Sustainable Development" (ESD) has been developed and is being implemented, according to which education itself has come to be understood as the most important factor in social change. The UNESCO World Conference on Education for Sustainable Development, held on November 10 - 12, 2014 in Aichi Prefecture, Nagoya City (Japan), completed the United Nations Decade of Education for Sustainable Development (2005 - 2014). The outcome of this conference was the Aichi Nagoya Declaration on ESD and the Implementation Plan for the Global Program of Action on ESD.

The above-mentioned features of environmental communications allow, firstly, to talk about their breadth, the possibility of including not only teachers and students in the communication process at the university, but also representatives of local communities, enterprises and public organizations. Secondly, ecological communications can be considered as a tool of an integral approach in education and a means of developing interdisciplinary connections, due to the fact that almost every discipline can see its ecological background. Thirdly, thanks to participation of students in environmental initiatives, as well as a wider immersion in environmental communications, they become interested not only in protecting the environment, maintaining environmental safety, but also in the socio-political component of this process. Namely, they can understand how to defend environmental rights in parliamentary-type structures, take part in local public hearings on environmental issues, and join youth parliaments. It is known that environmental volunteering leads many participants in these actions to understand the 
importance of political advocacy of this issue within any political party or social movement, primarily environmental.

Undoubtedly, the educational process creates the greatest opportunities for development of environmental communications in higher education. In recent years, new areas of training have emerged in higher education, reflecting the need of the modern world, and even more of the world of the future, for environmentally qualified specialists. Environmental topics are also firmly embedded in the content of many disciplines. For example, the Moscow Automobile and Highway State Technical University has an Energy and Ecology Faculty (EEF), where there is a direction of training "Technosphere Safety" in the bachelor's profile "Environmental Engineering " and curricula for the training of masters "Engineering Road Transport Complex" and "Sustainable Urban Transport". Corresponding member of the Russian Academy of Sciences (RAS) V.N. Lukanin is the initiator and head of the state scientific and technical program "Environmentally Friendly Car".

Most of the disciplines taught by the teachers of the Department of Sociology and Management of MADI include environmental topics in their content. Classes in these subjects contribute to formation of environmental competencies of students. $[9,10]$ As an example, we can refer to the problems of the course "Corporate Social Responsibility", which analyzes the principles of environmental management and the prospects for transition to a "green economy". [11] Students' attention is drawn to the model of environmental, social and corporate governance (eng. Environmental, Social, and Corporate Governance, ESG), which is a unity of management approaches aimed at maximizing involvement of company organizations in not only solving environmental, social and management problems that meet their commercial interests, but also the needs of local communities, as well as the environment, generally. In the classroom, students analyze this problem using examples of the functioning of the honey lines of the world's largest auto concerns (Rolls-Royce, Bentley, Porsche), which, having taken care of a sharp decline in the world's bee population, have created their own apiaries. Students also analyze the experience of the most successful startups (BeeHero and Edete [Israel], Pollenity [Bulgaria]), which, by developing and implementing various projects, help to combat the decline in the global population of bees, but also show examples of a responsible attitude to nature.

It is known that, despite the increased environmental responsibility of enterprises, until now it has not been possible to completely prevent the risks of man-made accidents causing enormous harm to nature. Therefore, in order to improve the environmental competence of students, and to understand the features of environmental communications in critical situations associated with natural disasters and man-made disasters, in a business game, students present projects of Russian companies related to elimination of the consequences of such emergencies. For example, students submit a report on the actions of the Russian mining and metallurgical company PJSC Norilsk Nickel to eliminate a diesel leak that occurred in May 2020 when a diesel fuel tank was depressurized at TPP-3 in Kayerkan (Norilsk region). This leak of oil products has created a threat to the ecosystem of the Arctic Ocean. Experience of Rosatom's actions to prevent an environmental disaster in Usolye-Sibirskoye city in the Irkutsk region, where one of the largest enterprises in Siberia, Usoliekhimprom, operated and after its closure left the environment poisoned by toxic chemicals is also interesting. Rosatom is the builder of enterprises for disposal of industrial waste throughout Russia, and an ecotechnopark is planned in the territory of Usoliekhimprom, which will also be involved in the waste processing process. The last example is most interesting from the point of view of the formation of students' environmental communications in that it makes it possible to see how such communications can be built not only horizontally between organizations and territories, but also vertically. 
Based on the materials related to this environmental problem, it is possible to compare how such communications were carried out in the past, are being carried out now and can be organized in the future, namely, with the greater use of information technologies. The attention of students in the course "Information resources and technologies in economics and management" is drawn to the gigantic possibilities of such communications.

In "Fundamentals of Personnel Safety" course the most important part is also the problem of environmental safety. This topic is raised in various forms of educational work, lectures, case studies, educational quizzes and business games. In the latter, namely, GIS technologies are used that help students to map objects mentioned in game plots, which also expands the environmental competence of students - future road engineers [12].

Experience of the teachers of Russian higher education allows us to assert that there are practically no academic subjects, the content of which would not allow use of training sessions to advance through the channels of environmental communications. Huge opportunities for such work open up when studying foreign languages. Presence of such opportunities is explained by combination of environmental and linguistic communications in the educational process. Students highlight the study of literature in foreign languages on environmental culture and the study of foreign languages itself as significant factors that play a decisive role in formation of their individual environmental culture, considering these areas of environmental communication as a component of intercultural communication. [13, p. 47 - 74]

Currently, an increasing number of university students can be attracted to participate in implementation of international environmental projects, and absolutely everyone who wants to - in local environmental actions in their higher educational institution and in the local community. Ecological tourism is becoming diverse in geography and rich in topics, where students are also involved. For example, from September 16 to September 27, 2013 in the Krasnodar Territory, events were held within the framework of the Student Ecological Tourism project, in which 32 students from the Russian State Social University (RSSU) from Moscow, Klin, Dedovsk, Maikop and Sochi took part. The organizers of this project were the Scientific and Pedagogical Center "Family, Gender, Demography" and the National Public Committee "Russian Family". The tourist direction of environmental communications can also be considered as such a means of military-patriotic education, which helps to form a sense of belonging to the great feats of ancestors, to develop students' interest in search activities.

\section{Conclusion}

A feature of environmental communications is their transboundary nature. Since the problems of nature are of a global nature, they can only be solved by universal efforts. Therefore, there is an international component in environmental communications. Thanks to the environmental information obtained during classroom work and self-study, the student does not just get acquainted with the environmental traditions of various countries, but with the help of this knowledge they build bridges to the culture and history of states and peoples.

Therefore, environmental education, which is a part of environmental education, opens up space for creation in higher educational institutions of the widest network of environmental communications, through which the student, already in the university period of his/her life, receives an education that meets modern needs, but also acquires the necessary skills to include not only in social life. This shall enable future specialists to solve complex environmental problems, which is an important prerequisite for immersing young people in wider public communications. 


\section{References}

1. O. Özdemir, H.U. Journal of Education, 43, 373 (2012)

2. I. Ugulu, M. Sakin, S. Baslar, Int. 1 J. of Educational Science, 5(4), 415 (2013)

3. A. M. Butters, Approaching Religion, 5(2), 67 (2015)

4. N. Reitter, J. of Conscious Evolution, 11(5) (2018)

5. S. Comfort, Y. E. Park, Environmental Communication, 12(7), 862 (2018)

6. M. Katz-Kimchi, Environmental Communication, 9, 367 (2015)

7. M. Katz-Kimchi, B. Goodwin, Environmental Communication, 9(3), 367 (2015)

8. R. J. Cox, Environmental Communication and the Public Sphere (2010)

9. L. Berényi, Regional formation and Development Studies, 8(3), 15 (2014)

10. M. Mulder, J. Gulikers, H. Biemans, R. Wesselink, J. of European Industrial Training, 33(8/9), 755 (2009)

11. O. Perfilova, Y. Alizade, (2011), Procedia-Social and Behavioral Sciences, 15, 2293 (2011)

12. S. Hryshchenko, V. Morkun, Metallurgical and Mining Industry, 4, 139 (2015)

13. L. M. Andryukhina, N. Yu. Fadeeva, J. De Negri, Education and Science, 19(8), 47 (2017) 